Fifth International Conference on Sustainable Construction Materials and

Technologies. http://www.claisse.info/Proceedings.htm

\title{
REINFORCED ALKALI-ACTIVATED CONCRETE WITH INDUCED CORROSION
}

\author{
Ongpeng, Jason Maximino C. ${ }^{1}$, Roxas, Cheryl Lyne C. ${ }^{1}$, Rubinos, Iona Trisha B. ${ }^{1}$, \\ Escleto, Andrew Teus T. ${ }^{\text {, }}$ \\ Tan, Sherie Joy M. ${ }^{1}$, Bolivar, Erica Mae C. ${ }^{1}$, Kalaw, Martin Ernesto L. ${ }^{2}$, \\ Promentilla, Michael Angelo B. ${ }^{3}$ \\ ${ }^{1}$ Civil Engineering Department, De La Salle University, Taft Ave, Manila, \\ Philippines, jason.ongpeng@dlsu.edu.ph, cheryl.capiz@dlsu.edu.ph. \\ iona_rubinos@dlsu.edu.ph, andrew_escleto@dlsu.edu.ph, \\ sherie_tan@dlsu.edu.ph, erica_bolivar@dlsu.edu.ph: \\ ${ }^{2}$ Mechanical Engineering Department, De La Salle University, Taft Ave, Manila, \\ Philippines, martin.kalaw@dlsu.edu.ph: \\ ${ }^{3}$ Chemical Engineering Department, De La Salle University, Taft Ave, Manila, \\ Philippines, michael.promentilla@dlsu.edu.ph:
}

\begin{abstract}
Reinforced concrete comprising of deformed steel bars is the common structural material in construction. The problem of this composite material is the corrosion of deformed steel bars inside the concrete that weakens the structure over time. In this paper, investigation on the two types of reinforced concrete were used: alkali-activated concrete (AAC) and ordinary Portland cement (OPC) concrete beams. In addition, Impressed Current Technique (ICT) was made to accelerate corrosion before performing flexural bending test. The use of a non-destructive test which is the digital image correlation (DIC) technique during the flexural loading test on the two types of beam were considered to monitor the strain values against load. It was concluded that AAC mixture 1:1:2 (coal fly ash: fine aggregate: coarse aggregate) with 12M Molarity and water binder ratio of 0.52 produced the lowest corrosion rate over time for all the beams. In addition, the strain values of the AAC mixture produced ductile behavior with strain softening effect on the third point bending load test where the location of the force was applied.
\end{abstract}

Keywords: Reinforced concrete, corrosion, alkali-activated concrete, ordinary Portland cement.

\section{INTRODUCTION}

In construction, concrete from ordinary Portland cement (OPC) wherein steel reinforcing bars are internally embedded is the common composite material used for various infrastructures. In recent years, the concept of alkali-activated concrete (AAC) has been one of the most studied areas in engineering and has been tested to be a potential alternative to OPC. The development of AAC as a construction building material leads to less carbon emission since it reduces or eliminates the use of OPC which produces significantly higher $\mathrm{CO}_{2}$ emission. One example of AAC is the use of 
coal fly ash (CFA). The CFA is one of the many ways of sustainably managing the large amounts of ash produced from coal-fired power plants especially in the Philippines (Kalaw et al., 2016).

All beam specimens of both concrete types were subject to accelerated corrosion using impressed current technique (ICT). However, Ahmad (2009) states that it takes months, or even years, to gain significant amount of corrosion in steel bars in concrete. Furthermore, the strain behavior of both AAC and OPC specimen under corrosion were measured using a non-destructive test called digital image correlation (DIC) during the flexural bending test. Non-destructive test using contact (Ongpeng et al. 2016) (Ongpeng et al. 2017) or non-contact (Ongpeng et al. 2018) method is nowadays significant since it can reduce the cost of prognosis and diagnosis of structures. The digital image correlation method is non-contact non-destructive test that utilized available measuring techniques for parameters such as axial strains from images that were generated through either artificial or experimental means. DIC is a commonly used technique in obtaining data such as displacement and local strain from experiments. Hoult, Take, Lee, \& Dutton (2013) reported that DIC is an available and alternative technique against the conventional strain gauge in the aspect of measuring strain.

\section{EXPERIMENTAL PROGRAM}

\section{Materials}

In this study, the AAC consisted of low-calcium CFA class $\mathrm{F}$ obtained from Bulacan, Philippines that was activated by sodium hydroxide $(\mathrm{NaOH})$. The elemental composition of the CFA obtained through X-Ray Fluorescence is shown in Table 1. Pellets of $\mathrm{NaOH}$ were mixed with water to obtain a solution molarity of $12 \mathrm{M}$.

Table 1. Elemental composition (wt\%) of the CFA

\begin{tabular}{|c|c|c|c|c|c|}
\hline $\begin{array}{c}\text { Silicon } \\
(\mathrm{Si})\end{array}$ & $\begin{array}{c}\text { Iron } \\
(\mathrm{Fe})\end{array}$ & $\begin{array}{c}\text { Aluminum } \\
(\mathrm{Al})\end{array}$ & $\begin{array}{c}\text { Calcium } \\
(\mathrm{Ca})\end{array}$ & $\begin{array}{c}\text { Potassium } \\
(\mathrm{K})\end{array}$ & Others \\
\hline 45.960 & 23.248 & 13.840 & 5.757 & 4.960 & 6.235 \\
\pm 0.098 & \pm 0.013 & \pm 0.163 & \pm 0.008 & \pm 0.010 & \pm 0.001 \\
\hline
\end{tabular}

There were two sizes of specimens made for AAC and OPC. The first specimens' size used $100 \mathrm{~mm}$ diameter $\mathrm{x} 200 \mathrm{~mm}$ high cylindrical specimens with uniaxial compression test according to ASTM C39 to make sure that the concrete was $20.7 \mathrm{MPa}$ in compressive strength. This is to ensure that the concrete achieved structural grade. The second specimens' size used beams of $100 \mathrm{~mm}$ x $100 \mathrm{~mm}$ x $400 \mathrm{~mm}$ length with flexural bending test according to ASTM C78 after accelerated corrosion in the reinforcing steel bars were made through ICT. During the flexural bending test of AAC and OPC, DIC was conducted to investigate the mechanical difference of both materials against load.

\section{Mixture Proportions of AAC}


Initially in laboratory condition, a total of 12 mixtures with 3 cylindrical specimens were made for AAC with the elemental composition shown in Table 1 and solution molarity of $12 \mathrm{M}$. Out of the 12 mixtures made, only 3 mixtures passed the minimum cylindrical compressive strength of $20.7 \mathrm{MPa}$. These are presented in Table 2 . The $\mathrm{NaOH}$ solution content of all mixtures was fixed at $20 \%$ of all the CFA. The waterbinder ratio was also shown in the table. The samples were cured through oven-drying at a temperature of $75^{\circ} \mathrm{C}$ for 48 hours after the end $7^{\text {th }}$ day where the removal of forms was conducted.

Table 2. Mixture proportions of AAC

\begin{tabular}{|c|c|c|c|c|c|c|}
\hline \multirow{2}{*}{ Mixtures } & \multicolumn{5}{|c|}{ Materials } & \multirow{2}{*}{$\begin{array}{l}\text { Water-binder } \\
\text { (w/b) Ratio }\end{array}$} \\
\hline & FA & Sand & Gravel & $\begin{array}{l}\mathrm{NaOH} \\
\text { solution }\end{array}$ & Water* & \\
\hline \multicolumn{7}{|c|}{ MixA using 4:1:1 w/b 0.476} \\
\hline $\begin{array}{l}\text { Ratio (by } \\
\text { volume) }\end{array}$ & 4 & 1 & 1 & $20 \%$ of CFA & - & \multirow{2}{*}{0.476} \\
\hline $\begin{array}{l}\text { Actual mass } \\
\text { used, kg }\end{array}$ & 5.796 & 1.449 & 1.449 & 1.159 & 1.6 & \\
\hline \multicolumn{7}{|c|}{ MixB using 1:1:1 w/b 0.438} \\
\hline $\begin{array}{l}\text { Ratio (by } \\
\text { volume) }\end{array}$ & 1 & 1 & 1 & $20 \%$ of CFA & - & \multirow{2}{*}{0.438} \\
\hline $\begin{array}{l}\text { Actual mass } \\
\text { used, kg }\end{array}$ & 3.2 & 3.2 & 3.2 & 0.64 & 0.76 & \\
\hline \multicolumn{7}{|c|}{ MixC using 1:1:2 w/b 0.520} \\
\hline $\begin{array}{l}\text { Ratio (by } \\
\text { volume) }\end{array}$ & 1 & 1 & 2 & $20 \%$ of CFA & - & \multirow{2}{*}{0.52} \\
\hline $\begin{array}{l}\text { Actual mass } \\
\text { used, } \mathrm{kg}\end{array}$ & 2.375 & 2.375 & 4.75 & 0.475 & 0.76 & \\
\hline
\end{tabular}

\section{Mixture Proportions of OPC}

The design mixture for OPC followed volumetric ratios shown in Table 3. Similarly, the cylindrical compressive strength was at least 20.7MPa.

Table 3. Mixture proportions of OPC

\begin{tabular}{|l|c|c|c|c|c|}
\hline & \multicolumn{4}{|c|}{ Materials } & \multirow{2}{*}{ Water-Cement ratio } \\
\cline { 2 - 5 } & Cement & Sand & Gravel & Water & \\
\hline Ratio (by volume) & 1 & 2 & 4 & - & 0.40 \\
\hline
\end{tabular}

\section{Beam Design for AAC and OPC}

Beams of size $100 \mathrm{~mm} \times 100 \mathrm{~mm}$ x $400 \mathrm{~mm}$ length were adapted for both AAC and OPC. The beams consisted of two (2) $8 \mathrm{~mm}$ main reinforcing deformed bars and three 
(3) $6 \mathrm{~mm}$ lateral reinforcing bars for each left and right ends of the beams. All steel bars used were specified at Grade 40. A pre-fabricated notch with size $5 \mathrm{~mm}$ x $10 \mathrm{~mm}$ was added to the beam specimens as well. This notch is to ensure that the mode of failure is by bending and with crack formation at the middle of the beam. Concrete cover was provided at $30 \mathrm{~mm}$ from the bottom of the beam, and $20 \mathrm{~mm}$ from the sides. The beam design is illustrated in Figures 1 and 2. A stainless steel bar was added in the middle of the beam to be used as the cathode in the ICT process where accelerated corrosion was conducted.

Note that all lateral reinforcements were wrapped in electrical tape to act as an insulator to resist electrical currents to ensure that accelerated corrosion would only affect the main bar. Nylon cable ties were also used to tie the lateral reinforcements to the main bars for the same reason as well. It was assumed that the electrical tape has little or negligible effect on the mechanical test made.

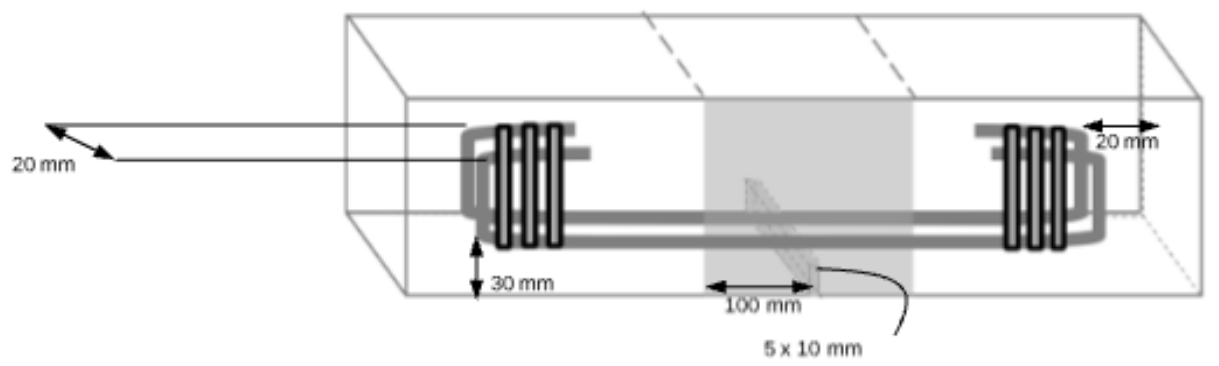

Figure 1. Isometric view of beam

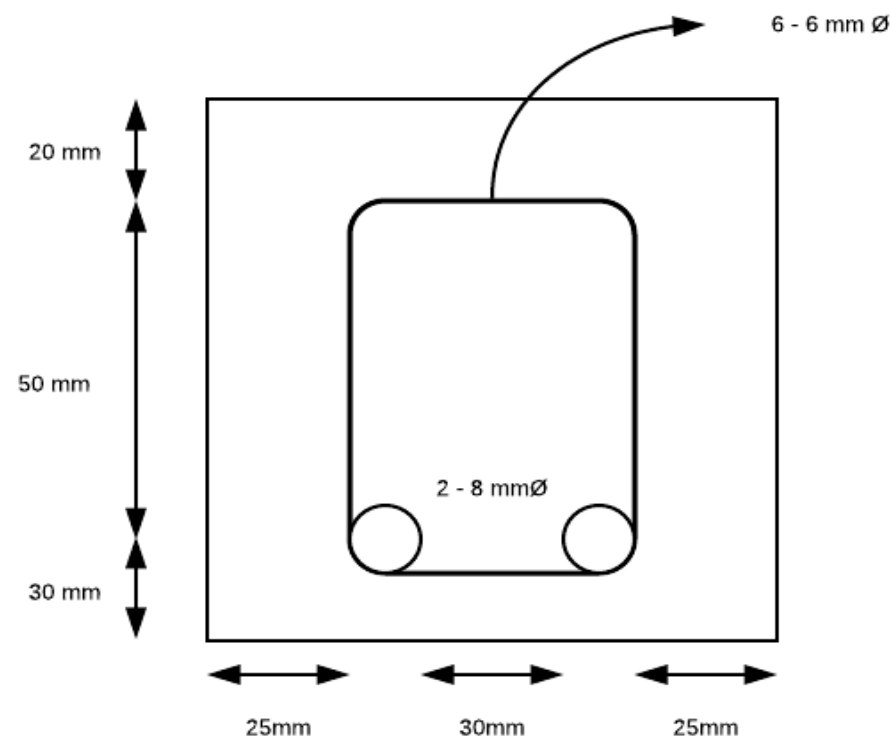

Figure 2. Front elevation view of beam 


\section{Test Method}

There were 15 concrete beams for OPC and 45 beams for AAC. The concrete beam specimens were air dried for 28 days. After which, the reinforcing bars were then corroded using ICT at Day 0, Day 7, Day 14, Day 21, and Day 28 (Ongpeng 2017). Prior to ICT, \#22-gauge wires were soldered to both ends of the main reinforcing bars. The beams were connected using a series connection, whereas the reinforcing bars acted as the anode and the stainless-steel bar as the cathode. Moreover, an AC/DC converter with a maximum capacity of $1 \mathrm{~A}$ was used in the circuit. The corrosion in the beams were measured using a CT-7 equipment. The CT-7 equipment acts as a potentiometer to evaluate the corrosion rate of steel in concrete.

The beams were then subjected to three-point bending flexural test. The force applied on the beam was loaded at step size of $5 \mathrm{kN}$ interval until specimen failure occurred. Each test per day of corrosion consisted of 3 specimens to ensure statistical stability on the data results.

A Nikon D3100 DSLR camera with 14-megapixel resolution was used in conducting DIC. It was used to capture the entirety of the flexural bending tests of each specimen through video. The video file was then converted to black and white photos in a .tif format to reduce noise in the images. Then, the images were correlated using the software GOM Correlate. Note that only the middle third portion of the beam surface was studied under DIC since the formation of cracks were focused on that plane surface.

\section{RESULTS AND DISCUSSION}

\section{Flexural Strength and Corrosion Rate of AAC and OPC}

The box plot of flexural strength and average corrosion rate with respect to time using ICT for AAC and OPC beam specimens are shown in Figure 3. It can be noticed that the flexural strength of all the beams for both concrete types fluctuated despite consistent increase of corrosion rate over time. According to Kearsley and Joyce (2014), there is an increase in the bond relationship of the concrete and steel from the corrosion of concrete slabs. At low levels $(<2 \%)$ of corrosion, it experiences an increase in the frictional forces at the concrete-steel interface due to a well adhering layer of rust (Chung, 1997). This explains the increase of flexural strength of the concrete despite corrosion wherein the early formation of corrosion increased the bond relationship of concrete and steel. However, the decrease in flexural strength can be associated to the relative mass loss occurring in the steel bars during accelerated corrosion.

Moreover, reinforced OPC beams are higher in flexural strength compared to all AAC shown in Figure 3. The corrosion rate for all beams increased with time using ICT as expected. The lowest corrosion rate with time was observed for all the beams is from the AAC mix of 1:1:2 w/b 0.520. The said mix had the optimum mixture of ingredients among AAC specimen because corrosion was highly minimized and resisted by the samples. 


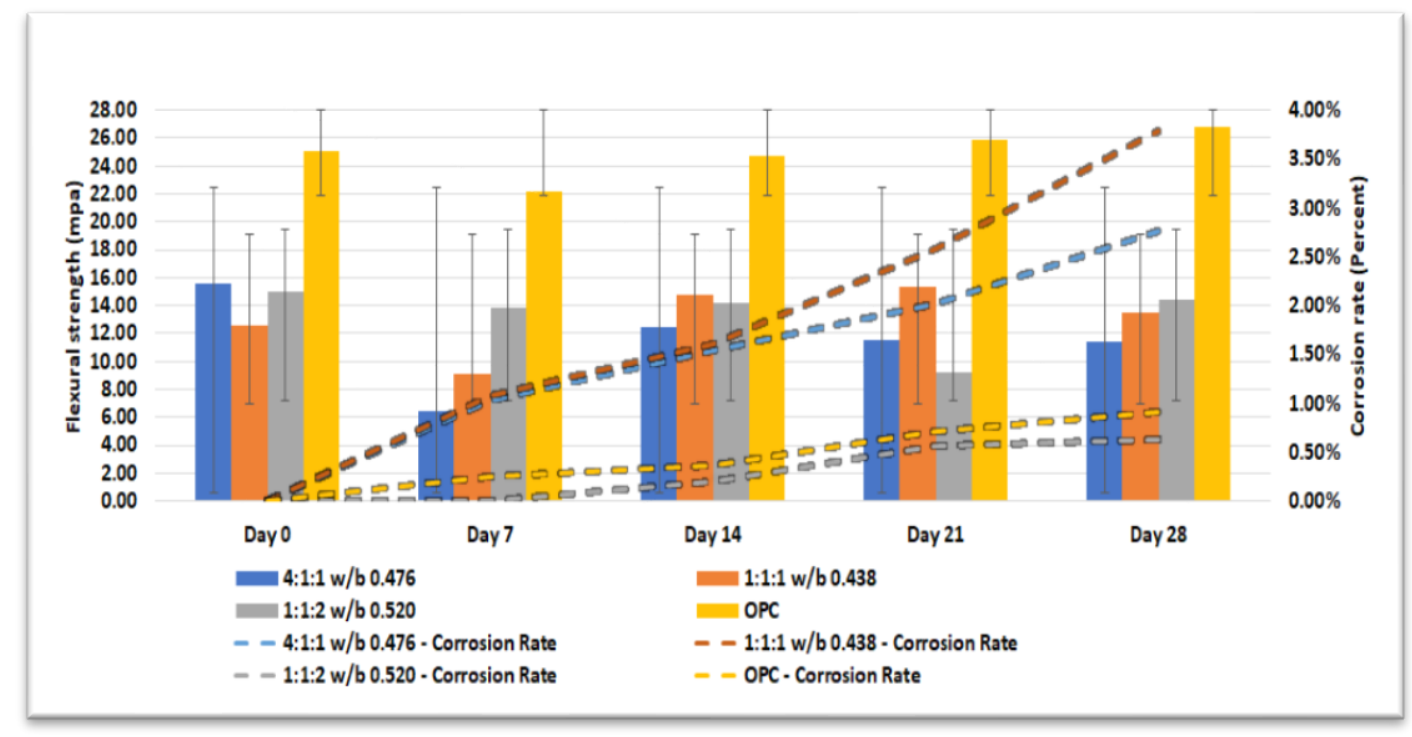

Figure 3. Flexural strength of AAC and OPC specimen

\section{Strain of AAC and OPC Beams using DIC}

For the analysis, the average percentage strains with box plots at peak loadings of both concrete types were compared. The comparison is illustrated in Figures 4 and 5. Note that the AAC mixture used for comparison against OPC is mixture $1: 1: 2 \mathrm{w} / \mathrm{b} 0.520$ as it has the highest flexural strength among all AAC mixtures with least corrosion rate for all beams presented. It is seen that AAC obtained higher strains than OPC at Day 21 and Day 28. The AAC strains are more consistent compared to OPC as well as the boxes that represent the interquartile range of data measured are shorter. It showed that OPC beams became brittle at older ages.

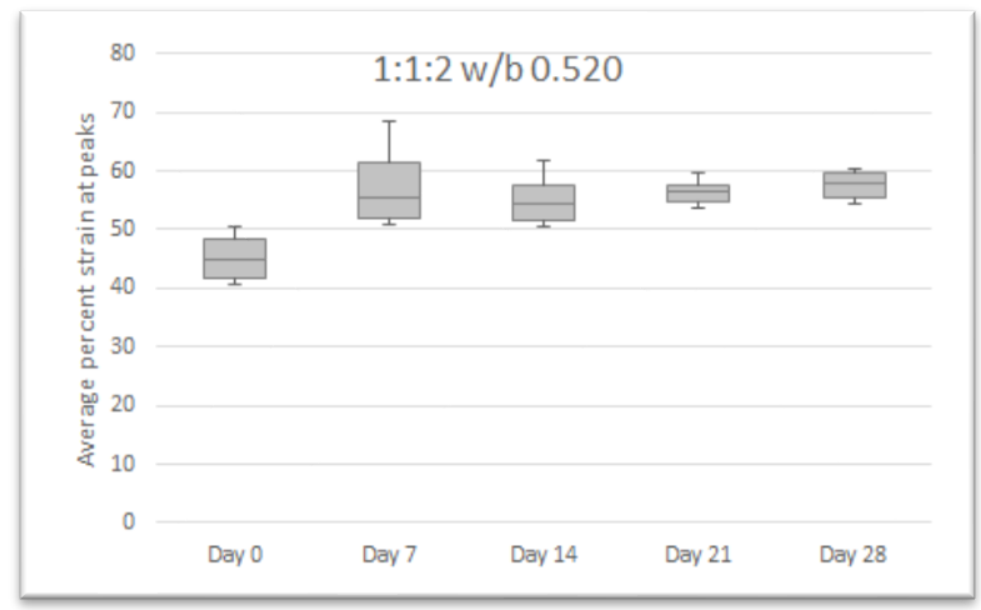

Figure 4. Box plot of percent strain at peaks for AAC per time 


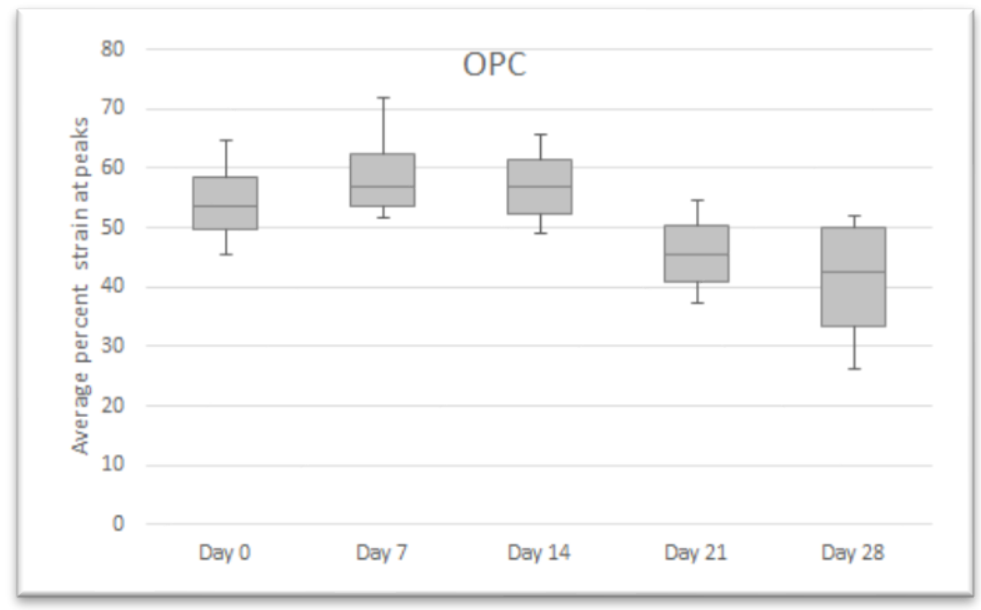

Figure 5. Box plot of percent strain at peaks for OPC per time

\section{Strain Localization of AAC}

During the flexural bending test, it was observed that AAC experienced a concave indentation beneath the concentrated load as shown in Figure 6, which is considered to be strain-softening. According to Bazant (1976), strain-softening is a failure due to unstable localization of strain which produces a local curvature within the beam. This type of failure produces a ductile region in the specimen, and the energy produced by the strain is stored within the localized curve of the beam.

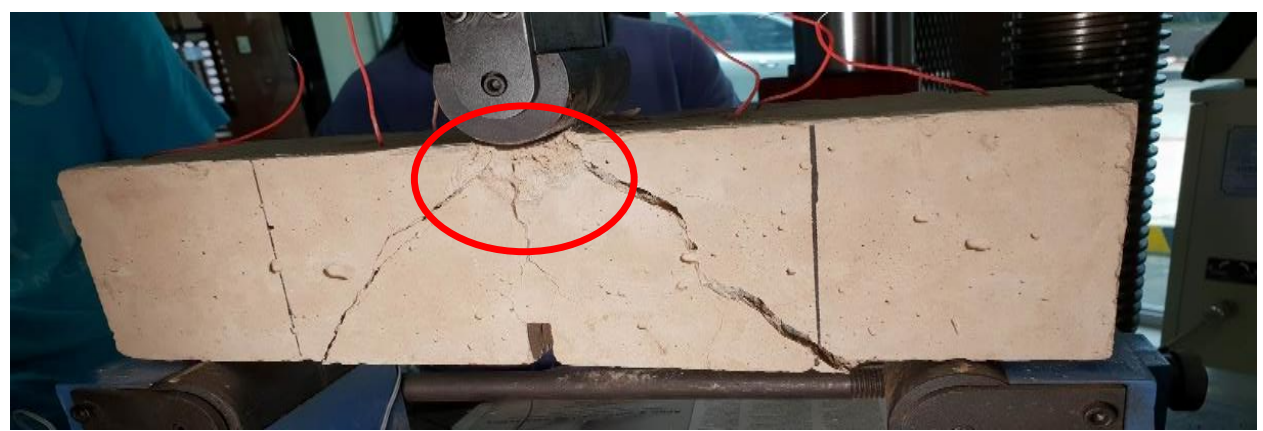

Figure 6. Strain localization of AAC beams

\section{CONCLUSIONS}

Development of new materials like Alkali-activated concrete (AAC) can help our construction industry in becoming sustainable. This paper used experimental tests to differentiate the application of reinforced AAC over OPC beams. In addition, Impressed Current Technique (ICT) was made to accelerate corrosion before performing flexural bending test. Use of a non-destructive test, digital image correlation (DIC) technique, during the flexural loading test on the two types of beam were considered to determine the strain values against load. The following conclusions could be drawn from the results of the study: 
(1) Flexural strength of OPC beams is higher for all AAC with equivalent or similar concrete cylindrical compressive strength of 20.7MPa.

(2) Flexural strength of OPC increased as corrosion rate increases (for corrosion rate less than $2 \%$ ).

(3) The least corrosion rate was experienced by AAC with mix of 1:1:2 (coal fly ash: fine aggregate: coarse aggregate) with water binder ratio of 0.520 with value less than $1 \%$.

(4) The AAC beam is a ductile material as it experiences strain softening under the point of concentrated load.

(5) There is no clear correlation between the effect of accelerated corrosion and flexural strength of both OPC and AAC due to fluctuating strength values despite consistent increase in corrosion.

\section{REFERENCES}

Ahmad, S. (2009). Techniques for inducing accelerated corrosion of steel in concrete. The Arabian Journal for Science and Engineering, 34, 95-104.

Bazant, Z. P. (1976). Instability, ductility, and size effect in strain-softening concrete. Journal of the Engineering Mechanics Division, 102(2), 331-344.

Chung, D. D. L., \& Fu, X. (1997). Effect of corrosion on the bond between concrete and steel rebar. Cement and Concrete Research, 27(12), 1811-1815.

Hoult, N. A., Take, W. A., Lee, C., \& Dutton, M. (2013). Experimental accuracy of two dimensional strain measurements using Digital Image Correlation. Engineering Structures, 46, 718-726. Retrieved on July 12, 2017 from doi:10.1016/j.engstruct.2012.08.018

Kalaw, M. E., Culaba, A., Hinode, H., Kurniawan, W., Gallardo, S., Promentilla M. A. (2016). Optimizing and characterizing geopolymers from ternary blend of Philippine coal fly ash, coal bottom ash and rice hull ash. Materials, 9. Doi: 10.3390/ma9070580

Kearsley, E. P., \& Joyce, A. (2014). Effect of corrosion products on bond strength and flexural behaviour of reinforced concrete slabs. Journal of the South African Institution of Civil Engineering, 56(2), 21-29

Ongpeng, J., Oreta, A., Hirose, S. (2016). Damage progression in concrete using acoustic emission test through convex hull visualization. ACI Materials, 113 (6), 737-744.

Ongpeng, J., Oreta, A., Hirose, S., Nakahata, K. (2017). Nonlinear ultrasonic investigation of concrete with varying aggregate size under uniaxial compression loading and unloading. Journal of Materials in Civil Engineering, 29 (2), doi:10.1061/(ASCE)MT.1943-5533.0001726 
Ongpeng (2017). Ultrasonic pulse velocity test of reinforced concrete with induced corrosion. ASEAN Engineering Journal, 7(2), 9-17.

Ongpeng, J., Oreta, A., Hirose, S. (2018). Contact and noncontact ultrasonic nondestructive test in reinforced concrete beam. Advances in Civil Engineering, Article ID 5783175, https://doi.org/10.1155/2018/5783175 